\title{
EL PRIMER EDWARDS BELLO O EL NOVELISTA ANTES DE EL ROTO*
}

\author{
THE FIRST EDWARDS BELLO OR THE NOVELIST BEFORE EL ROTO
}

\author{
Jaime Concha \\ University of California, San Diego \\ USA \\ jconcha@ucsd.edu
}

\begin{abstract}
Resumen: Antes de El roto (1920) que da renombre a su autor afirmándolo en su condición de novelista, Joaquín Edwards Bello publica una serie de escritos en que se cuentan sus primeras narraciones, El monstruo y El inútil. Ambas salen a luz muy cerca del centenario de la Independencia; ambas guardan una relación siamesa que hace productivo cotejarlas. El tema común de las desilusiones juveniles -la chispa de lo valedero se apaga pronto en sus personajes- da paso a una incisiva exploración del carácter nacional en el que la familia y la clase pesan con peso opresivo. Monstruosidad e inutilidad resultan ser, así, sintomas de una sociedad que Edwards empieza a observar con talento y creciente lucidez.
\end{abstract}

Palabras clave: novela chilena; Joaquín Edwards Bello; familia; clase social; nación.

Abstract: Before El roto (1920) which gave its author a wide audience in South America and across the Hispanic world, Joaquín Edwards Bello wrote a number of texts which include his two earliest narratives, El monstruo and El inútil (not yet translated into English). Both novels were published by the Centennial; both keep a

\footnotetext{
" Este artículo surge de una conferencia dictada en la Universidad de Concepción (noviembre de 2018), dentro del marco de un seminario de investigación dirigido por el profesor Edson Faúndez V., director del programa de Doctorado en Literatura Latinoamericana.

Dediqué esta conferencia a Salvador Benadava, profesor de francés, colega y amigo, expulsado de la Universidad de Concepción en 1973. Salvador fue un lector asiduo de Edwards Bello. En su departamento en el centro de Concepción vi una colección de sus libros que había ido reuniendo cuando pocos dedicaban atención al escritor. Por más de una década, Benadava exploró sistemáticamente el archivo Edwards. Años antes de morir publicó un estudio que subtituló "Una aproximación a Joaquín Edwards Bello" (2006), que con razón se considera haber propulsado el interés por el autor que hoy nos convoca.
} 
close connection between them, inviting useful comparisons. The theme of loss -lost ideals, lost illusions, lost faith in political values, etc.- allows an intensive exploration of the national character, dominated by the opression of family and social class. Monstrosity and idleness seem thus to be symptoms of a society that Edwards Bello begins to observe becoming an outstanding chronicler, witness, and critic of Chilean life.

Keywords: Chilean novel; Joaquín Edwards Bello; family; social class; nation.

Recibido: 19/01/2021. Aceptado: 15/04/2021.

$\mathrm{P}$ ara un lector medianamente educado, por lo menos de tiempo atrás, Joaquín Edwards Bello es ante todo el autor de El Roto (1920) y el cronista que, por largos años, dejó en el diario La Nación sus impresiones sobre Chile, los chilenos, la chilenidad y múltiples temas históricos o de actualidad. Para alguien un poco más curioso, es también el autor de una o dos novelas (quizás la misma con doble título) sobre Valparaíso, puerto donde se crió y al que contribuyó a dar rostro literario. Todavía un lector más informado podría verlo como el creador de la novela internacional hecha en nuestro país, con compatriotas paseándose por París, Madrid u otras ciudades del turismo europeo de la época. Co-creador, más bien, pues se le había adelantado el último Blest Gana con Los trasplantados (1904) y con Gladys Fairfield (1912).

En esta ocasión quisiera hablar de dos de sus novelas, ambas muy tempranas, publicadas en torno al primer Centenario: El inútil, de 1910, concluida el año anterior, y El monstruo, fechada en 1911. Constituyen las piezas más destacadas de lo que podría considerarse la prehistoria de Edwards Bello, es decir, sus escritos anteriores a la primera versión de $E l$ Roto (La cuna de Esmeraldo, 1918). Así, lo que voy a exponer se centra en las novelas mencionadas, refiriéndome a otras publicaciones cuando sea esclarecedor ${ }^{2}$.

${ }^{1}$ El inútil, Santiago, Imprenta Barcelona, 1911. Al parecer hubo varias reimpresiones de esta primera edición. El monstruo, Imprenta y Litografía La Ilustración, 1912.

${ }^{2}$ Comentario aparte requerirían los Cuentos de todos colores (1912), ajenos en su mayoría a la orientación dominante en la escritura de Edwards en esos años. Jorge Edwards glosa el más realista, "La primera aventura", cuyo tema es la iniciación sexual. Más interesante me parece, aunque muy inmaduro, "Roldanini o el gran experimento", narración fantástica con sorprendentes anticipos de muchos inventos técnicos posteriores. 
Empiezo con dos notas marginales y un breve comentario sobre un libro distinto de los mencionados. Las notas son una personal, la otra marginal en sentido propio.

Una de las delicias de quien lee al primer Edwards Bello es comprobar que con él se comienza a perfilar una galería de personajes de nuestra tradición narrativa. Entre Martín Rivas novecentista y Luis Bernales que lo seguirá (el héroe de Un perdido, 1918); al lado de Juana Lucero y de los intensos mineros de Lillo, Eduardo Briset Lacerda, el protagonista de $E l$ inútil, es sin duda menos memorable, pero resulta ilustrativo de una fase conflictiva en la evolución del país. Si yuxtaponemos el personaje de Blest Gana al de Edwards, es posible observar un continuum en que el antipático suche de don Dámaso Encina se hace ahora totalmente tortuoso y desleal a sus principios, convicciones e ideales. Una cierta imagen convergente del chileno se configura a inicios del siglo, más que nada del chileno que participa en política. La diferencia, desde luego, reside en los narradores, en la bonhomía constante perceptible en Blest Gana y en la acidez, amargura, negación y hasta rencor manifiestos en Edwards. Los suyos -sus espíritus- son anverso y reverso, temperamentos novelísticos diametralmente opuestos.

Mi segunda observación tiene que ver con las notas marginales que descubro en una primera edición de El inútil. Al parecer, pertenecen a dos lectores diferentes, uno que escribe con tinta roja y en inglés, otro que con lápiz de mina se complace en corregir errores de dicción (galicismos, solecismos, etc.) que halla en el texto. ¿́Gringo uno, castizo el otro? El primero anota, por ejemplo: "he already said that" y, seguramente con ironía, se refiere "al mito de la superioridad chilena". El segundo parece obsesionado por los elementos naturalistas que cree detectar y por los novelistas que menciona el autor. Uno es claramente un profesor de literatura hispanoamericana, quizás estadounidense, de los años cuarenta o cincuenta. En todo caso, ambos muestran una atención minuciosa en sus lecturas.

Cerca también de 1910, Edwards publica un libro muy diverso, esta vez de viaje. Tres meses en Río de Janeiro (Santiago, Imprenta La Ilustración, 1911) narra y describe su estancia brasileña los últimos meses de 1910. Sus preliminares le confieren un fuerte coeficiente de alteridad. "De otras notas de viaje" es un breve texto de Maupassant que Edwards transcribe en francés. Lo sigue un pasaje en que "otros cielos... otros mares" se reiteran 
con deliberación. Si no es el hallazgo prístino de la alteridad por parte de Edwards (ya ha estado previamente en Europa), ello consolida una mirada al exterior que afina la consciencia de su ser, de la tierra a que pertenece.

Probablemente el núcleo del libro sea el reportaje de las dos sublevaciones de la escuadra a que asiste en la bahía de Río. Junto con mostrar el reportero de terreno que después llegará a ser en su calidad de cronista de la guerra civil española, nos muestra también la vacilación en su mirada y en su juicio. Comienza admirando al hombre del pueblo que dirige la rebelión, el mulato João Candido (o João Clemente), para terminar criticando a los parlamentarios que decretan la amnistía de los rebeldes.

Las páginas últimas del libro, notables a mi ver, no están exentas de sorpresas. La más seria es la implacable denuncia que allí se hace de los sucesos de la Patagonia -y esto en pleno centenario de la república. Los masacradores de fueguinos aparecen con nombre y apellido: son los Menéndez, los Brown, los Stebenrauch, todo en boca de la autoridad incuestionable de Monseñor Fagnano, superior de los Salesianos en Punta Arenas. La denuncia, frecuente en la prensa argentina, no era muy común en Chile. La de Edwards es una denuncia temprana y valiente de lo obrado por la Sociedad Explotadora de Tierra del Fuego y de las artes "civilizadoras" de nuestro país en el extremo sur del territorio.

Con ánimo diferente, con gran autoironía, Edwards se refiere al constante interés que muestran los viajeros por uno de sus apellidos. ¿Cuál es la relación que él tiene con don Agustín? De modo pertinente a cuestiones que nos ocuparán en seguida, Joaquín se define aquí como un Edwards de segunda clase. Un segundón en la familia, por lo tanto. Si recordamos los grandes y malvados segundones de Shakespeare y los menos memorables del teatro del Siglo de Oro español; y si tenemos en cuenta el largo lapso en que rigió la institución del mayorazgo, vemos que la broma del autor se llena de sentido. 'Segundón' pudiera equivaler a excluido del tronco principal del clan Edwards. La injusticia social y familiar sólo subsanada a inicios de la época moderna (aquí conocemos el pago de Chile que se dio a O’Higgins por suprimir los mayorazgos) dejó tal vez en él más de una marca emocional, una cicatriz inconsciente.

En El inútil de la familia (2004), el actual escritor Jorge Edwards lleva a cabo una lectura del corpus de su tío que prácticamente lo reescribe por entero. Con razón Grínor Rojo llamó a esta operación "Edwards multipli- 
cado por Edwards" (2006). El título que dio a su libro, amén de privilegiar una de las obras de que voy a hablar, define un rasgo distintivo en la personalidad literaria de su célebre pariente. El eco de El idiota de la familia, de Sartre acerca de Flaubert, suena curiosamente ambiguo, al combinar prestigio personal y marginalidad social ${ }^{3}$.

En un momento del ensayo-ficción se afirma lo siguiente: "el monstruo, que es como decir de nuevo el inútil, pero con un rasgo de autodenigración mayor, con un trazo añadido definitivamente más negro" (Edwards, 2004: 101-102).

La puntualización de Edwards me recordó un hecho personal. Estando en Stanford de profesor visitante y hurgando en su bien nutrida biblioteca, di con las primeras ediciones de las novelas iniciales de Edwards Bello. No las leí completas, pero lo que alcancé a leer fue suficiente para comprobar lo que afirma su sobrino: se trata de una y la misma novela. Quedé entonces con ganas de analizar alguna vez este binomio narrativo, cosa que hago ahora. Como la igualdad no es total, aprovecho sus disparidades -brechas, bifurcaciones- para echar luz recíproca entre ellas. Esto, teniendo en cuenta que, si bien Jorge Edwards comenta exhaustivamente El inútil, no se ocupa para nada de El monstruo.

Los dos textos poseen una estructura lineal, son progresivos en lo cronológico. Concretamente, El inútil se abre con el nombre del protagonista, menciona sus antecedentes genealógicos, toca su difícil educación, etc., recorriendo los círculos sociológicos de la familia, del grupo y de la clase a medida que transcurre el relato.

Las novelas comparten también una común bipartición. Más nítida y definida en El monstruo, en El inútil funciona a nivel de estructura profunda. En efecto, a la zona europea y al retorno a Chile, precede el despertar adolescente del sujeto en su propio país.

Por razones históricas y culturales fácilmente reconocibles, por lo cual es innecesario recordarlas, una buena porción de las novelas latinoamericanas de la primera mitad del siglo pasado se articula en torno al viaje europeo. Cambaceres en Argentina, el primer Rómulo Gallegos, para no hablar de otros, diseñan un formato que se extenderá hasta el vanguardismo

${ }^{3}$ El inútil de la familia, Santiago, Alfaguara, 2004. 
de Rayuela y la novela histórica de Carpentier. El "allá y el acá, el acá y el allá”, la formula mágica acuñada por el escritor cubano, es el signo y divisa de este tipo de relatos. Época que ya ha quedado atrás, hoy que la globalización permite imaginar un turismo más vasto, variado y ecuménico.

Los títulos de las novelas son igualmente expresivos. Es decisivo, por ejemplo, que la primera vez que se menciona lo "útil", valor antitético al "inútil", sea en relación con un arma de muerte, la pistola con que Eduardo pretende suicidarse. Para un inútil como él, lo único útil sólo puede ser lo destructivo, lo que quita la vida (1911a: 16). En el caso de El monstruo, la imagen es de raíz material, mecánica, y deriva en última instancia del famoso título de Zola, La bestia humana, referido al tren. Los monstruos más tempranos e insistentes que aparecen en su obra son los acorazados que ve en Brasil. También aquí lo que prima es la destrucción, en este caso de la violencia y de la guerra. Cuando se hable más tarde de los placeres malsanos de París, la imagen será la del "engranaje de una monstruosa máquina” (1912a: 20). Más revelador es, sin embargo, el cambio de plano que traslada la idea al corazón del mundo económico y social. Leemos en El inútil:

Una concurrencia especial asistía al 'Restaurant del Gallo de Oro'. Todos eran honrados obreros, grandes y vigorosos, deformados sus cuerpos por los rudos trabajos. Los albañiles con la cara y las manos curtidas por el contacto de la cal. Uno de los que trabajaba en las canteras ostentaba una órbita vacía, volado el ojo por la chispa cortante de una piedra. Los demás tenían las espaldas encorvadas y las manos monstruosas, erizadas de callosidades duras como los instrumentos de trabajo que manejaban. (1911a: 25).

Y después: "El capitalista, pensaba, será mirado en un siglo más, cuando se haya operado la revolución social, como el esqueleto de esos monstruos deformes que vivieron en época remota y; la humanidad los recordará avergonzada como recordamos hoy a Nerón y a Heliogábalo" (1911a: 95). Si juntamos estos pasajes y glosamos el pensar del personaje, se deduce que el monstruo crea lo monstruoso. La riqueza excesiva del capitalista crea la deformación monstruosa del obrero, y el cuerpo social completo participa de esta deformación generalizada.

El inútil viene precedido de un "para empezar", breve texto introduc- 
torio que, aparentemente simple, da lugar a un montaje de circunstancias que busca explicar la gestación de su obra. Se trata, en general, de su iniciación como escritor.

Entramos, primeramente, en una atmósfera colectiva con gente que bebe y conversa en voz alta. Son escenas de club o de restorán, en las que importa el talento o el ingenio que exhiben los interlocutores. La frase, la ocurrencia original resalta como manifestación de un intercambio vivo e inteligente. El autor (porque es del autor de quien se trata, más adelante se lo llama Joaquín) quiere retener esos momentos exquisitos para que no se desvanezcan en la nada. Estamos, pues, en un espacio bohemio, donde reina una chispeante esgrima oral.

Un chroniqueur que solo habla en francés le sugiere escribir sus pensamientos, para revelar (y la precisión es importante) "les erreurs de la société" (1911a: 4). La picazón de la escritura aflora entonces por primera vez.

De ahí pasamos a una circunstancia muy personal, íntima de su vida. La amiga con quien habla es una amistad de infancia, sin duda la misma Florita, que será la amada en sus memorias de En el viejo almendral (1943). Equivale a la Jenny de El inútil y a Inés en El monstruo. Es el mismo, idéntico recuerdo. La carta que envía a ese amor que no fue, es valorada por el padre de ella como la de un escritor en ciernes. Lo que empezó como escena pública se convierte ahora en algo privado, secreto, lleno de emoción. Tal es el mito de orígenes que nos cuenta Edwards a propósito de su condición de escritor.

De modo paralelo, en el preliminar de El monstruo, "Un trago amargo para empezar", el autor se defiende de los ataques que recibió su primera novela. Acusa a los lectores de no entender la facultad y los poderes de la imaginación. El habría sacado de la nada al sujeto de El inútil y al país de su relato. Teniendo en cuenta la vena autobiográfica que recorre toda su obra, esta apología pro domo sua es poco convincente. Los entendidos del ambiente santiaguino vieron con claridad el carácter de una novela en clave que ellos podían descifrar. Nosotros, salvo una que otra, hemos perdido las pistas.

Más persuasivo es su rechazo a la mentalidad comercial y al afán de dinero reinantes antes en la nación. "Porcópolis" llama a la capital por la sucia actividad mercantil a que se entrega. Probablemente hay aquí un motivo sincero en la incipiente ideología de este "inútil". No hay que olvidar 
que, con Rodó y su Ariel (1900), un nuevo espiritualismo recusaba el lucro utilitarista y la reducción de la vida humana a valores puramente instrumentales.

Comparado con el número y densidad de episodios que contiene $E l$ inútil (idilio campestre, creencias e ideas políticas, pensión de Valparaíso, libertinaje moral en París, adulterio y muerte de la madre, etc., para limitarnos solo a su primera parte), El monstruo se presenta con una textura más lisa y homogénea, donde el caer y decaer de Francisco Jimenal en la capital francesa da paso a una dulce y blanda "regeneración" cuando vuelve a su patria ${ }^{5}$. Nada hay allí del "cambio radical" al que se aspira inicialmente en El inútil.

El primer capítulo de esta novela, relativamente extenso, ofrece una fuerte lógica interna y un nexo composicional que encaja en el conjunto de la narración. La obsesión del muchacho que deja de ser niño y entra en la adolescencia, es la religión o, más exactamente, la fe, una fe que pierde muy pronto. En adelante, le mostrará asco, desprecio y un odio extremo. Explican esta actitud no solo las "gracias" de nuestra Santa Madre Iglesia, sino también prejuicios y estereotipos heredados del anticlericalismo novecentista. Es posible que también estén de por medio elementos de la leyenda negra protestante fomentados en ámbito sajón. Esto lo induce, por compensación, a una cosa también de época: el recurso evangélico, es decir, el retorno a una religiosidad primitiva centrada en la figura de Jesús. Dicho de otro modo: de los tres componentes principales que observan en el fenómeno religioso un Schleiermacher o un Dilthey, el personaje desecha la superestructura de ideas, teológica, y las prácticas y ritos que considera mera hipocresía, para refugiarse únicamente en el factor del sentimiento, la religiosidad como algo espiritual inscrita en el corazón humano. De he-

${ }^{4}$ Rodó asiste al centenario de la Independencia en Chile y pronuncia en el Congreso Nacional una conferencia que es uno de sus peores escritos.

${ }^{5}$ En contraste con la onomástica de Blest Gana, de marcada sorna antioligárquica, la de Edwards es más difícil de descifrar. Jimenal es uno de tantos apellidos con la misma terminación: Orregal (Orrego Luco, sin duda), Juncal, Carrascal, Carranzal, Cabral forman serie. Todavía en Criollos en París aparece un Florencio Carvajal, que caracteriza a un diplomático "experto" en la cuestión de Tacna y Arica. Más interesante, tal vez: Edwards traduce a Edwards, implantando el apellido del ricachón en el nombre de pila del sujeto. Edwards es algo así como un Edwards usurpado y expropiado, que el personaje luce en el pecho cual condecoración y en la frente como un estigma. Es el secreto que el joven Edwards Bello se atreve a prenderse en el ojal. 
cho, con una curva formal casi perfecta, el capítulo concluye con una escena de idilio campestre, casi roussoniano, donde surge su amor por Aurora.

Más interesante aún, por ser de mayor alcance para la coherencia temática de la obra, son las estrategias psíquicas con que el sujeto se defiende de la depresión al ser expulsado del colegio. Le gustaría evadirse a Alaska o California, e incluso intenta suicidarse, como ya indiqué. En este respecto, al visualizar su cuerpo destruido en una fantasía póstuma, lo hace pensando en un obrero que vio recientemente morir en un motín. Como se verá, esto prepara el desenlace de la novela, y pone el dedo en un fondo sangrante y conflictivo de índole esencial: la profunda ambigüedad ideológica que rige todo el texto.

La noción clave en estas novelas es, sin lugar a dudas, la de cambio, el cambio que experimentan los personajes a lo largo del trayecto narrativo. Sus implicaciones y consecuencias son numerosas, en lo psicológico, en lo moral y, en relación directa con nuestro autor, en connotaciones ideológicas y caracterológicas.

El personaje novelesco, siempre insatisfecho de su situación en el mundo, lucha contra los obstáculos que le niegan la posibilidad de salir de su estado. Busca transformarse, pero su voluntad de cambio tropieza a menudo con su propia debilidad moral. Las intenciones no corresponden a los actos. Y como esto se manifiesta ante todo en el ámbito de la política, el sujeto toma consciencia de no estar a la altura de sus ideales. El quiebre le provoca un nuevo desasosiego. Por último, la mirada de observador antropológico que práctica el autor, determina que muchas supuestas certezas acerca del carácter nacional se vuelvan problemáticas.

Algunas puntualizaciones previas. El cambio es un elemento central en toda estructura novelesca, desde la época grecorromana hasta tiempos modernos, en los que se hace más explícito y acuciante. Tampoco los maravillosos romans medievales están exentos de esta dimensión. No hay que olvidar que el concepto mismo de aventura, imprescindible en la trama narrativa, se lo suele derivar del participio futuro, neutro, del verbo "advenio". "Aventura" es lo que advendrá, el advenimiento de Cristo al fin del viaje y la búsqueda del caballero.

La situación de cambio se relaciona a la vez con el vector temporal. El paradigma de la conversión, tanto filosófico como religioso, deslumbró a más de un personaje, especialmente a los de estirpe romántica. Los autores 
realistas y naturalistas del siglo XIX, y los del realismo social norteamericano del XX (S. Lewis, Th. Dreiser), dieron primacía por el contrario al cambio gradual, sucesivo, evolutivo, que hacía subir al héroe peldaño a peldaño en la escala económica, para hacerlo caer después hasta el fondo del abismo social. A la novela contemporánea, la que anticipa Dostoievsky con sus Memorias del subsuelo (1864), se atribuye como rasgo característico el cambio radical de existencia a que aspiran los héroes. Ahora bien, es curioso -y raro- hallar en El inútil un párrafo como este:

Un deseo indefinible lo aguijoneaba hacía tiempo; una esperanza incierta que acariciaba sin cesar-la intuición de un cambio radical que se operaría en su vida por la aparición en su camino de algo que necesitaba, de una cosa que vendría a llenarle un vacío- no sabía dónde y qué le alegraría su existencia solitaria (1911a: 21).

Esta aspiración a un cambio súbito, decisivo, va a contrastar y a echar más sombra sobre Eduardo cuando fracase en poner en práctica sus ideales. Todos estos hechos adquieren mayor relieve contra el fondo de tensión social que cruza la novela en su totalidad. Presente y visible en las frecuentes referencias a motines y al uso de la fuerza represiva, ella se interioriza, haciéndose conflicto latente, oscuro y subjetivo. El estatus inestable que hemos visto caracteriza la situación social del autor -la condición "secundaria" de Edwards para decirlo con sus propias palabras- lo lleva a acercarse al pueblo de un modo confuso y ambiguo, a veces francamente contradictorio. El pueblo chileno, según él, es generoso, combativo, etc., pero los líderes que representan su causa son insinceros, oportunistas y solo critican la codicia de los ricos hasta que pueden acceder a ella. El estereotipo es banal y perdura hasta el día de hoy -lo que no quita que en ciertos casos peque de verdadero. El personaje del Político es un ejemplo claro de este retrato sesgado del pueblo; y la imagen de "El profesor anarquista", que retratará más tarde en un espléndido y malhadado capítulo de En el viejo almendral (1943: 81-89), consolidará con rigor esta visión.

Es evidente que los aires nacionalistas que el anotador subrayaba en la novela deben mucho al ensayismo dominante a comienzos de siglo. Lentamente Edwards ampliará su marco de percepción, llegando a hablar, en su libro misceláneo de 1918, La cuna de Esmeraldo, de una América indo-mediterránea y, en los años veinte y treinta, de un nacionalismo con- 
tinental. En el primer caso se hacía eco de la insatisfacción que, primero en Argentina y luego en el Perú, se manifestaba en torno a nuestra evasiva identidad hemisférica. En el segundo llegaba hasta converger con postulaciones del mejor Vasconcelos y de su credo iberoamericanista y también, por desgracia, del peor Vasconcelos, el posterior a su derrota de 1929: un cierto hispanismo trasnochado, nostalgia del periodo colonial, simpatía y hasta admiración por los regímenes fascistas europeos.

El capítulo final de El inútil lleva a un clímax el choque social en una escena que, en parte, recuerda el episodio del motín de Urriola en Martín Rivas, aunque de un modo más brutal y complicado. El autor reserva a este desenlace una perfecta unidad dramática, en una secuencia que empieza con el despertar pacífico del personaje y se cierra con su muerte en plena noche. El centro es una protesta obrera organizada en contra de la ejecución del anarquista catalán Francisco Ferrer en Barcelona, la que es aplastada a sangre y fuego por las fuerzas de orden, la policía y el ejército 6 . Edwards narra con aguda y notable precisión las vacilaciones de Briset, su oscilación mental, el zig-zag entre la simpatía que siente por los obreros y su reflejo en favor del grupo represor. Sin transición admira el coraje de un huelguista y admira la gallardía del comisario que da la orden de hacer fuego. Lamenta la muerte de este y lamenta en seguida la muerte de una mujer del pueblo, pintada con todos los rasgos de una "petrolera" rediviva. En un principio trata de abanderarse con las víctimas de la represión, para luego integrar una partida de jóvenes aristócratas del Club La Unión. Si, como quiere Emerson, "el héroe es un hombre inmutablemente centrado", el vaivén de nuestro sujeto lo sitúa en los antípodas del heroísmo. Morirá en su hogar, en el seno de su clase, condenado a ser señorito por los siglos de los siglos. Rechaza, eso sí, los consuelos del sacerdote. La novela se cierra con gran circularidad, volviendo a lo que empezó como una negación visceral de la farsa eclesiástica. "Mentira" es la exclamación última que se pronun-

\footnotetext{
${ }^{6}$ Para una breve semblanza del anarquista catalán y de las circunstancias que llevaron a su ejecución, puede leerse de James Joll, The Anarchists (Cambridge, Mass., Harvard University, 1980, 215-220). Para la situación del anarquismo en Chile, ver los trabajos de Sergio Grez Toso; entre ellos, el más reciente es "Los primeros anarquistas de la "región chilena". Perfiles humanos", en El movimiento obrero y las izquierdas en América Latina (Ed. por Hernán Casmamero y Martín Mangiastini, Raleigh, N.C., Editorial A Contracorriente, 2018).
} 
cia en El inútil. Ella condensa la descreencia en las ilusiones de lo alto y la no-verdad de una vida acá en la tierra regida por la hipocresía social. Todo este final, demás está decirlo, no solo es raro en la literatura del país, sino extremadamente perturbador desde un punto de vista ideológico.

El final de El monstruo pudo ser también un capítulo estupendo. Pudo serlo, pero no lo fue. Tal como está, resulta fallido, incluso trivial. La intención, atrevida en sí misma, era crear una disonancia entre el casamiento de Fernando y la obsesión o idea fija que asalta su mente. Durante el domingo en que ocurre el "acontecimiento social" (1912a: 250), todo es "un cuadro de luz y movimiento" (1912a: 251). Las pinceladas ácidas, frecuentes en la novela, desaparecen como por encanto, dando paso a la armonía y a un idilio generalizado. En la utopía pueblerina, ricos y pobres conviven, simbolizando algo así como una panacea nacional: "la plaza...bullía como en los días de las fiestas nacionales" (1912a: 251). Pero ello está a punto de derrumbarse cuando el novio, corroído por el remordimiento y la consciencia de su traición, se ve invadido por escenas y el sonido de cuecas prostibularias. Esto, en el mismo templo y en el instante de la bendición matrimonial. Es una hiriente astilla que se incrusta en medio de la solemnidad del espectáculo religioso. Aunque todo termina bien, blandamente, con el sujeto sometiéndose a la mentira ritual, pocas veces se ha estado tan cerca de penetrar en el inconsciente de una clase alta. La alucinación queda enclavada, oscuramente, entre las luces del idilio provinciano. Líneas después leemos esto: "En la frente del monstruo se despertó un sueño olvidado de glorias futuras. Tras esos jardines; más allá de esos cerros, se extendían en los valles las grandes ciudades que ahora iba a dominar, porque al rebelde sucedía el hipócrita, el hombre útil a la sociedad" (1912a: 262).

iNunca mejor dicho! Así se enlazan las dos novelas y los dos protagonistas, el inútil de una y el monstruo de la otra que termina siendo útil a la sociedad y a su clase. Para un escritor como Edwards, estigmatizado en su familia como el inútil por excelencia, la monstruosidad residía más bien en sucumbir a sus prejuicios y entregarse a la mentira de sus valores e instituciones.

La mezcla de la ficción con lo autobiográfico, simbiosis constitutiva de buena parte de la novela moderna, ha venido acrecentándose en los últimos tiempos, lo que no deja de ser preocupante. En la gran novela clásica lo que había era la fusión entre los dos componentes; lo que tiende a darse 
ahora es mas bien la fisión, la interferencia entre uno y otro. En Stendhal, en Hardy, Tolstoy o Thomas Mann, la experiencia personal enriquecía sin duda, incorporándose a la plasmación de un mundo pleno e integrado -la "mónada" literaria del celebre ensayo lukacsiano de Logos (1910) -. Pero desde que los autores empezaron a contarnos cuánto y cómo les costaba empezar a escribir, a abrirnos su closet de intimidades, este factor se hipertrofia y se interpone entre la obra y el lector. Entre nosotros, Blest Gana, Manuel Rojas y Bolaño representan momentos progresivos de un proceso del que no sabemos adonde nos llevará. La autoficción, reducida a juvenil mitología personal, no nos amplia, sino que trivializa y deforma nuestra experiencia del mundo.

Según Jorge Edwards, Joaquín trabajó casi siempre elaborando "autorretratos parciales" (2004: 101). El juicio es correcto, pero es un juicio de hecho, factual. Lo que importa es la valoración de tal hecho. ¿̇Hasta qué punto esa manera de novelar, que vale en efecto para la mayor parte de sus ficciones, no perturba su visión y su práctica narrativa? Esto resulta especialmente válido para las piezas de que hemos hablado.

¿En qué medida los caracteres de El inútil y de El monstruo son proyección de su propio carácter? De ser así, tendríamos una extraña forma de autoficción nada neutra ni enaltecedora, sino un autorretrato corrosivo y destructor de sí mismo. ¿En qué medida el carácter que atribuye a los chilenos y, sobre todo, a los círculos de la elite que frecuentaba son su carácter encarnado en los demás? Si este fuera el caso, ċasistiríamos a la peculiar ontología de un personaje que es el mismo "monstruo", con cabeza y corazón propios, pero con el cuerpo y pies de barro que asigna al país? Más que ontología, entonces, pura teratología, muy apta y funcional. ¿Proyección degradada de sí mismo? De ser así, se trataría no solo de la identidad personal y familiar, sino de la degradación de una identidad socialmente limitada, la de su propia clase.

Desde el punto de vista técnico, la estrategia es sencilla y fácil de reconocer. El método consiste simplemente en incluir al crítico en lo criticado, en involucrar al personaje en aquello que niega y le repugna. Se coloca al protagonista en total convivencia con la enfermedad que diagnóstica. La crítica social resulta, así, destino y némesis del héroe. Su talón de Aquiles será la flecha envenenada con que le regala y le bendice el país que lo vio nacer. 
Más arduo es abordar la cuestión ideológica que se desprende de todo esto. Salvador Benadava, quien pregunta directamente en su libro: "Cómo y dónde situarlo desde un punto de vista ideológico?” (2006; 64), da enseguida una muestra bastante extensa de los intentos de respuesta. Entre ellas, destaco una inteligente observación de Jorge Teillier (no hay que olvidar su formación de historiador), quien plantea: "Personaje y escritor contradictorio, conviene considerar con cuidado sus declaraciones. Un nacionalista puede tomarlo como chovinista, un izquierdista puede acusarlo de fascista" (2006: 65). No es tanto el contenido proposicional del juicio lo que nos interesa, sino la forma relacional que adopta: Edwards mirado aquí por un adversario eventual. Lo cual confirma no solo el carácter constantemente provocador de sus escritos, sino una relación siamesa con el contrario, el valor antagonístico que marca toda su obra.

Con toda seguridad, el ejemplo más flagrante de incoherencia lo suministra un pasaje de El monstruo. Jimenal, el protagonista, ha perdido su dinero en un casino cercano a París; está totalmente arruinado. Cruza la ciudad en busca del tutor que lo sacará de apuros. Con brillante pulso literario, el autor nos describe al personaje en su trayecto de ida y vuelta. Primero, al atravesar barrios pobres y modestos de la ciudad y al ver el trabajo de simples obreras y de jóvenes costureras, toma nota y se hace cargo de "la vergonzosa desigualdad social" (1912a: 59) que impera en la capital. Luego, ya de vuelta y con plata en el bolsillo, desandando los mismos lugares, exclama complacido: "en Paris no hay miseria" (1912a: 62). Se ve bien: la esquizofrenia ideológica del sujeto es perfecta7 ${ }^{7}$. Ahora bien, mucho antes de que el distingo fenomenológico entre autor y escritor se impusiera en la teoría literaria, ya Valéry había entrevisto que el hombre verdadero que produce una obra no es el mismo que la obra hace suponer. A pesar de esta reserva, es bien claro que hay una acusada convergencia entre el novelista y los compatriotas que circulan por sus novelas. Al retratar a la colectividad de su tiempo, al hablar de los múltiples defectos arraigados en la nación, el

\footnotetext{
${ }^{7}$ Ya que se cita a Maupassant, vale la pena recordar que en Bel-Ami (1885) el protagonista, Georges Duroy, pasea por el Bois de Boulogne contemplando con rabia y desprecio a "hipocrites aristocrats", sintiendo de inmediato que entre ella y él hay "algo en común". La misma pulsión contradictoria se deja entrever en la escena de la iglesia de la Trinité donde Duroy compadece a un pobre penitente para, en seguida, reaccionar con desapego y frialdad.
} 
autor nos deja un precioso autorretrato en las entrañas del triste Leviatán en que le tocó vivir ${ }^{8}$.

Es evidente que las novelas estudiadas no figuran en el cuadro mayor de nuestra narrativa nacional. Son obras incipientes de un escritor que, pese a sus muchos méritos posteriores, nunca ha sido parte del canon más alto en la literatura del siglo XX. Quizás su amplia y rica producción periodística contribuyó al desvió de los críticos en un tiempo en que creación literaria y periodismo no solo se veían separados, sino con perspectiva jerárquica. Aun Darío, que tanto hizo por superar esa concepción, aceptaba la distinción, postulando un periodismo culto, noble, por encima de la crónica noticiosa y del fait divers. Hoy, cuando todo esto ha cambiado, es posible ver a Edwards Bello en la lógica interna de sus escritos, en la variedad e interacción de ellos. De hecho, Cecilia García-Huidobro, que tanto ha hecho por corregir la situación, constata un renovado interés por nuestro autor, identificándolo en varios libros significativos, como los mencionados de Jorge Edwards y de Salvador Benadava, junto a la publicación, tan esperada, de las Crónicas reunidas. Habría que agregar, por supuesto, sus propias aportaciones. Un escritor de la magnitud de Edwards Bello está esperando que se reediten muchas de sus obras, hoy inhallables, y que se estudie monográficamente cada uno de sus libros.

En lo que acabamos de ver -y confieso que es muy poco- queda pendiente el carácter del chileno que el autor se plantea con tanta pasión. Si asentimos a su veredicto, tendríamos que conceder que, para él, lo que caracteriza al chileno es su falta de carácter. La esencia del chileno consistiría

\footnotetext{
${ }^{8}$ Un último escrúpulo. Un estudio mas completo de estas novelas requeriría abordar la cuestión del juego, el juego de azar. Habito y pasión dominante del escritor, es aquí una situación narrativa que prueba el carácter del personaje. Los casinos franceses y, más tarde, el hipódromo santiaguino o porteño son un tiempo y espacio que funcionan como extracoordenadas en la consciencia del sujeto. El girar de la ruleta y la velocidad de los caballos fascinan y dan vértigo al jugador. La apuesta, con su mezcla de suerte y de experiencia falible, busca conjurar la irrealidad del dinero a sabiendas de su poder destructor y realísimo. Lo aleatorio es, así, la puerta estrecha para acceder al dominio y orden de la necesidad. Tal vez esto tenga algo que ver con el anticapitalismo instintivo y frívolo del protagonista. Jugar es luchar contra el fantasma más tangible del capital. En el pasaje de El monstruo que he puesto de relieve la consciencia social, aunque precaria y fugaz, es consecuencia del fracaso y de la pérdida en el juego. Por otra parte, es curioso que Edwards no mencione el terminacho "ludópata" que Carol Arcos me hace saber que existía ya en el siglo XIX. (Ver su excelente articulo "Rosario Orrego: Alberto, el jugador (1860)", Historia Crítica de la Literatura Chilena, LOM, 2018, II, pp. 261-5).
} 
en su patética falta de carácter. La traición a sus ideales, la dilapidación del propio talento son sus marcas definitorias. Ya que hay no pocas referencias a parábolas evangélicas en sus novelas iniciales, podría estar soterrada la de los talentos, la del derroche de los dones con que la vida dota a una persona. ¿Es verdad lo que nos dice y postula? ¿Ha sido toda nuestra historia una historia de gente sin carácter, hecha y malgastada por quienes carecían de carácter?

En su obra, es difícil hallar paradigmas realmente positivos. Quien vio en el quintralismo y en el carrerismo dos estigmas emblemáticos de nuestro devenir colectivo, es renuente a reconocer personalidades heroicas y ejemplares. La única que sobresale, y tampoco de un modo enterizo, es la de Balmaceda, siempre presente en su obra temprana y al que no dejará de dedicar un buen número de crónicas. En la fase que nos ocupa, su balmacedismo no es el íntimo y emocional cultivado por D’Halmar, sino algo distinto y tornasolado. Hombre de genio como pocos, se lo ve como un Ícaro sacrificado al sol de su ambición (1911a: 50). En otro registro y en la misma novela, responde con un enérgico "merde" -la gran interjección de Cambronne- a espiritistas que no cesan de molestarlo en su solaz de ultratumba (1911a: 113-114). Más que todo, su recuerdo y su legado se hicieron carne del pueblo, que lo celebra y le rinde culto hasta en los burdeles. Este inconsciente presidencialista, que aparece por primera vez en esos años y que llegará hasta Droguett, es uno de los aciertos de mitología popular observado por el novelista. Sin consciencia política explícita (los políticos fueron los primeros en traicionar la causa balmacedista), Balmaceda ingresa en el seno del pueblo aún en un escritor escéptico y criticón como el que empezaba a ser Edwards Bello.

\section{Referencias bibliográficas}

Arcos, Carol. (2018). "Rosario Orrego: Alberto, el jugador (1860)”, en Historia Crítica de la Literatura Chilena II. Santiago: LOM, pp. 261-265. Barrios, Eduardo. (1918). Un perdido. Santiago: Imprenta Chilena. Benadava, Salvador. (2006). Faltaban sólo unas horas... Aproximación a Joaquín Edwards Bello. Santiago: LOM. 
Blest Gana, Alberto. (1904). Los trasplantados. Vol. I y Vol. II. París: Garnier Hermanos.

Blest Gana, Alberto. (1912). Gladys Fairfield. París: Casa editora de Garnier Hermanos.

Edwards Bello, Joaquín. (1911a). El inútil. Santiago: Imprenta Barcelona.

Edwards Bello, Joaquín. (1911b). Tres meses en Río de Janeiro. Santiago: Imprenta La Ilustración.

Edwards Bello, Joaquín. (1912a). El monstruo. Santiago: Imprenta y Litografía La Ilustración.

Edwards Bello, Joaquín. (1912b). Cuentos de todos colores. Santiago: Imprenta Barcelona.

Edwards Bello, Joaquín. (1920). El roto. Santiago: Editorial Chilena.

Edwards Bello, Joaquín. (1943). En el viejo almendral. Santiago: Editorial Orbe.

Edwards, Jorge. (2004). El inútil de la familia. Santiago: Alfaguara.

Grez Toso, Sergio. (2018). "Los primeros anarquistas de la 'región chilena'. Perfiles humanos”, en Hernán Casmamero y Martín Mangiastini editores. El movimiento obrero y las izquierdas en América Latina. Raleigh, N.C.: Editorial A Contracorriente.

Joll, James. (1980). The Anarchists. Cambridge, Mass.: Harvard University, pp. 215-220.

Maupassant, Guy de. (1885). Bel-Ami. París: Ollendorf.

Rodo, José Enrique (1900). Ariel. Montevideo: Imprenta de Dornaleche y Reyes.

Rojo, Grínor. (2006). "Edwards multiplicado por Edwards", Atenea, N ${ }^{\circ}$ 494: 189-199. 